\title{
Research on the University English Flipped Classroom Reforms from the Perspective of Teaching Academic
}

\author{
Zhou Yun \\ School of Foreign Languages, Yuxi Normal University, Yuxi, Yunnan 653100 \\ hunter2011@foxmail.com
}

Keywords: Teaching academic, English teaching, Flipped classroom, Implementation steps.

\begin{abstract}
Teaching academic is a systematic and specialized knowledge related to teaching work, and it is also the abilities and qualities represented by university teachers in teaching practice. Based on academic teaching, the paper systematically discussed university English flipped classroom reform approaches, first, analyzed the basic understanding for the basic theory introduced to the academic university English flipped classroom reform, and then, this paper design flipped classroom university English reform program, in which the author first discussed the advantages that flipped classroom guides university English teaching practice, then put forward specific action that flipped classroom guide university English teaching practice, aiming to provide a reference for universities implement English flipped classroom teaching reform.
\end{abstract}

\section{The basic understanding of teaching academic basic philosophy introduced into the reform of university English flipped classroom}

Teaching academic philosophy refers to teachers' understanding, views, ideals and beliefs for the university teaching, including university teachers' teaching concept, knowledge, practice teaching concept. University teaching academic philosophy can play a guiding role for university teaching and training research personnel. Personnel training is the basic functions of the university, as well as the fundamental task and teaching is its main channels. In the university, the student must be centered, and teachers need to improve teaching quality and train more qualified personnel. Reasonable teaching academic philosophy can guide the university teachers to know what to teach and how to teach. Construction of teaching academic philosophy can deepen university teachers' teaching knowledge, to change the traditional approaches taking teaching just as a task to complete. After the proposed academic teaching, it is able to train university teachers' professional autonomy, professional skills and professional beliefs. The basic understanding of teaching academic basic philosophy introduced into the reform of university English flipped classroom has advanced guiding significance, and it has certain forward-looking to take flipped classroom as a means for teaching reform.

The advantages that flipped classroom guides university English teaching reform from the perspective of teaching academic

Help to develop students' self-learning ability. The essence of flipped classroom implementation process is to reverse the two traditional teaching mode processes "knowledge transfer" and "knowledge internalization". Knowledge transfer process is transferred from the classroom to the next class or family, and knowledge internalization process transfer from the class to the classroom or home. So, from the two dimensions of time and space, it achieved a complete reversal for the learning process, which is a new "first-learning post-teaching" paradigm. In addition, in the students' knowledge internalization process, teachers accompany and participate, which helps students in a timely and with effective manner to solve the problems. In the process of discussion and cooperation between the students, the students can really digest the course content, so that the "knowledge internalization" can play maximize utility, so that teaching effectiveness and learning can both have a qualitative leap. This is precisely the greatest advantage of flipped classroom compared to traditional classroom. 
Help to promote flipping and upgrading the role of teachers and students. Traditional teaching mode mainly takes the classroom as a place for teachers to impart knowledge to students, to explore how to achieve knowledge transfer utility maximization within a fixed period of time and limited space, namely, how to arrange transport and teaching process of teaching content to achieve optimal results and a high order state. Such teaching model focused the optimize knowledge transfer process in the teaching activities, but neglect that the students are the true subject in the learning process, ignoring the original level of the individual student and the ability to accept differences, and it makes it impossible to achieve a serious shortage of play for each student to differentiate different levels of teaching, However, the flipped classroom uses online learning and differentiated integration of the guidance mode, which helps students complete knowledge absorption and internalization to the maximum extent and gives full play the main role of students in the learning process. Flipped classroom effectively realized students' individual differences in development, and classroom function has also been effectively played with the improvements in the process, making up for the lack of play in the traditional teaching mode and achieving the value of effective classroom demands.

Helps to develop new teacher-student relationship. In the traditional model of classroom teaching, the teacher as the main operator of knowledge transfer, in the classroom, always have near-absolute right to speak. "Teacher-centered" teaching status makes teacher in an absolute dominant position in the original equal relationship. Students are in a subordinate position, which greatly suppressed and hindered the students' bold innovation and courage to quest. In contrast, the classroom activities in the flipped classroom transferred from single lecture to two-way interactive communication, creating a diversified interaction mechanism between teachers and students, between students and students, forming a three-dimensional multi-dimensional communication mechanisms, increasing the interaction between teachers and students exchange and emotional communication, which helps students improve knowledge internalization ability to effectively cultivate students' creative thinking, divergent thinking, logical thinking and ability to self-exploration.

Helps to promote the re-integration and optimal allocation of educational resources. By creating micro-video, teachers can use the network and the integration of modern information technology to integrate the best colleges and universities English education resources in different countries or regions. Teachers put these resources into the micro-video, for independent learning, make up and heal their regional differences, so that different levels of college students can enjoy the best of the elite educational resources, implementing "no difference of knowledge transfer" effectively compensated that English teaching is ineffective, due to differences in individual teachers' knowledge base, teaching methods and teaching level. It breaks the monopoly of high-quality educational resources, making each student in different countries or regions have the opportunities to receive the highest quality education. The restructuring and the allocation of educational resources in flipped classroom is unmatched by traditional teaching model. In the process of re-integration and optimization of educational resources configuration, flipped classroom truly realized fair education.

\section{The specific operation: flipped classroom instruction university English teaching}

Clear teacher's role and positioning. In the flipped classroom teaching mode, in college English teaching throughout the process, college English teachers need to complete changes from the "teacher-centered" to "student-centered", Teachers need to adjust the attitude, change the concept of recognition of new teacher-student relationship" to eliminate sense of hierarchy and release from the near-absolute right to speak, teachers are no longer the authority of imparting knowledge, but the doubts mentor to assist student learning. As a guide, teachers need to understand each student's potential and advantages inherent intelligence, to grasp and understand the extent of the difference between their learning progress of differentiation, make a good grasp of how to provide students with differentiated "one to one" counseling. In the limited time and space within the classroom, the teacher effectively solve difficult puzzles each student to promote their 
personality development, abandoning stereotyped popularization teaching. These changes have put a great challenge for teachers, need to improve the ability of teachers proficient in business, along with a full range of excellent coaching skills (including the ability to integrate resources, judgment, professionalism, business skills, communication skills, collaboration skills and interpersonal skills).

Increase teachers and students IT literacy. In today's society, the increasing popularity of computers, extensive use of the Internet and the rapid development of cloud technology make our lives enter the era of big data. IT has quietly penetrated into all areas of life, the education sector has not escaped this baptism. If we want to successfully use flipped classroom in college English teaching practice, both teachers and students should effectively improve their IT literacy and computer skills. First, teaching video production put forward higher requirements for teachers' level of information technology, only having a certain amount of information technology and computer application skills, taking heavy and difficult courses and other information elements into a dapper video, and design detection exercises complying curriculum, teachers can customize the real-time tracking of students learning progress and knowledge to grasp the situation. Similarly, only with a certain basic level of computer application, students can use computer terminals, tablet PCs or smart phones and other mobile terminal prior to the effective completion of independent study and practice lesson before class targeted. Therefore, IT should not be an obstacle to the level of college English teaching to carry out a new model flipped classroom, teachers and students two sides should strengthen their IT literacy and computer application level, which is not only a effectively flipped classroom interaction basis and premise, but also is a effective protection of the concrete practice.

Enhance students' self-learning ability. The effect students independently study courses in micro-video before class directly affect the implementation and results on the flipped classroom "inside knowledge". In the traditional teaching model, teachers unidirectional transfer knowledge to students, but in the flipped classroom, that change for the students viewing the micro-video knowledge reverse implement exploration. This is completely transformed and useful supplement to the knowledge transfer process, which put forward higher requirements for students' self-learning ability and self-discipline. Before class, the students become the learning pace automatic regulator, choosing the learning time and space according to their own learning, learning to master content and learning amount of progress and pace. In class, students participate in the exchange interaction with teachers and students, in the discussion, they continue to expand and create some new breadth and depth knowledge. The promotion of students' self-learning ability and the development of personalized learning make students life-long benefit, which is the fundamental way to really improve the effectiveness of college English teaching, and it is the only choice to achieve the student's education change from school to lifelong-education.

\section{References}

[1] G.L. Zhou, H.Q. Ma. Teaching academic skills: a new framework for faculty development and evaluation . Education Research, 2013,08: 37-47.

[2] J.H. Shi, T. Xu, Y.F. Li. Study on the University Teachers' Teaching Academic Situation Based on the Survey 44 universities. Higher Education Research, 2011,12: 52-66.

[3] X.L. Zhao. Flipped classroom in the process within the knowledge and teaching model design . Modern Distance Education Research, 2014,02: 55-61.

[4] J.L. Zhang, Y. Wang, B.H. Zhang. Research flipped classroom teaching. Journal of Distance Education, 2012,04: 46-51.

[5] X.F. Chen. Research flipped classroom teaching mode. Central China Normal University, 2014.

[6] C.X. Song, Yu Kaishet. Flipped classroom projects based on teaching mode. Journal of Distance Education, 2014,01: 96-104. 